\title{
ACFA 2020 - AN FP7 PROJECT ON ACTIVE CONTROL OF FLEXIBLE FUEL EFFICIENT AIRCRAFT CONFIGURATIONS
}

\author{
R. Maier \\ EADS Innovation Works \\ Munich 81663, Germany
}

This paper gives an overview about the project ACFA 2020 which is funded by the European Commission within the 7th framework program. The acronym ACFA 2020 stands for Active Control for Flexible Aircraft 2020. The project is dealing with the design of highly fuel efficient aircraft configurations and, in particular, on innovative active control concepts with the goal to reduce loads and structural weight. Major focus lays on blended wing body (BWB) aircraft. Blended wing body type aircraft configurations are seen as the most promising future concept to fulfill the so-called ACARE (Advisory Council for Aeronautics Research in Europe) vision 2020 goals in regards to reduce fuel consumption and external noise. The paper discusses in some detail the overall goals and how they are addressed in the workplan. Furthermore, the major achievements of the project are outlined and a short outlook on the remaining work is given.

\section{INTRODUCTION}

Blended wing body type aircraft are promising high efficiency due to a smaller wetted area compared to classical tube/wing configuration and also due to a lower structural weight. The BWB configuration also offers a great potential for the minimization of noise signature through integration of the engine over the rear fuselage or in the airframe and also due to the generally higher wing area/weight ratio, which allows for a simplified high-lift system. The structural weight can be further minimized thanks to implementation of active loads control developed in ACFA 2020. Active control is also applied to improve the ride comfort by minimizing the structural response to turbulence and, of course, has to provide appropriate handling qualities. Due to the unconventional placement 
of control surfaces, BWB type aircrafts require new multichannel design methods and architectures, in particular, for active loads and vibration control.

Moreover, new promising active control concepts such as adaptive feedforward control and neural network control are investigated in ACFA 2020. The adaptive feedforward control concept to control turbulence-induced structural vibrations has been even validated by flight tests on the DLR ATTAS (Advanced Technologies Testing Aircraft System) experimental aircraft. The control concepts are applied to two aircraft models. In a first step, a large flying wing aircraft for 750 passengers designed in the VELA (Very Efficient Large Aircraft) and NACRE (New Aircraft Concepts Research) project [1] is used. For that purpose, an aeroelastic model has been generated based on the geometry and structural design as performed in the NACRE project. Main application case is a newly designed, ultraefficient 450-passenger aircraft. For this 450-passenger aircraft, a predesign for a flying wing and an ultrawide body fuselage aircraft with carry-through wing box (CWB) have been performed and both designs have been compared, in particular, with respect to fuel efficiency. Due to the significant better fuel efficiency, the BWB design has been retained for the further work in the project. In the final phase of the project, the structure of this new 450-passenger aircraft will be resized taking into account the attained loads reduction by active control. This will lead to further weight saving and improvement of fuel efficiency. The paper describes the workplan and major goals of the project and presents some selected results. Detailed technical results can be found in $[2-15]$ and the papers belonging to the special sessions dedicated to ACFA 2020 of the EUCASS 2011 conference [16-25].

\section{ACFA 2020 WORKPLAN AND PARTNERSHIP}

As outlined in Fig. 1, the main drivers for the ACFA 2020 project were defined by the ACARE vision 2020, which targets for a strong reduction of the fuel consumption and noise emissions of aircraft. In the meantime, ACARE presented the new "Flightpath 2050" as updated Europe's Vision for Aviation with even more challenging targets for fuel efficiency and reduced noise emissions until 2050. Emissions of $\mathrm{CO}_{2}$ should go down by $75 \%$ and perceived noise emissions should be reduced by $65 \%$ compared to a typical new aircraft in year 2000 .

ACFA 2020 is focussed on two major challenges. First of all, European research on highly efficient aircraft configurations in the projects VELA and NACRE [1] was concentrated on very large aircrafts for more than 700 passengers but the biggest market share in long haul flights is taken by smaller mid-size aircraft. Therefore, ACFA 2020 deals with the design of an ultraefficient mid-size aircraft. Hereby, a BWB configuration has been compared to a more conventional aircraft with ultrawide body and CWB. The second and major challenge 


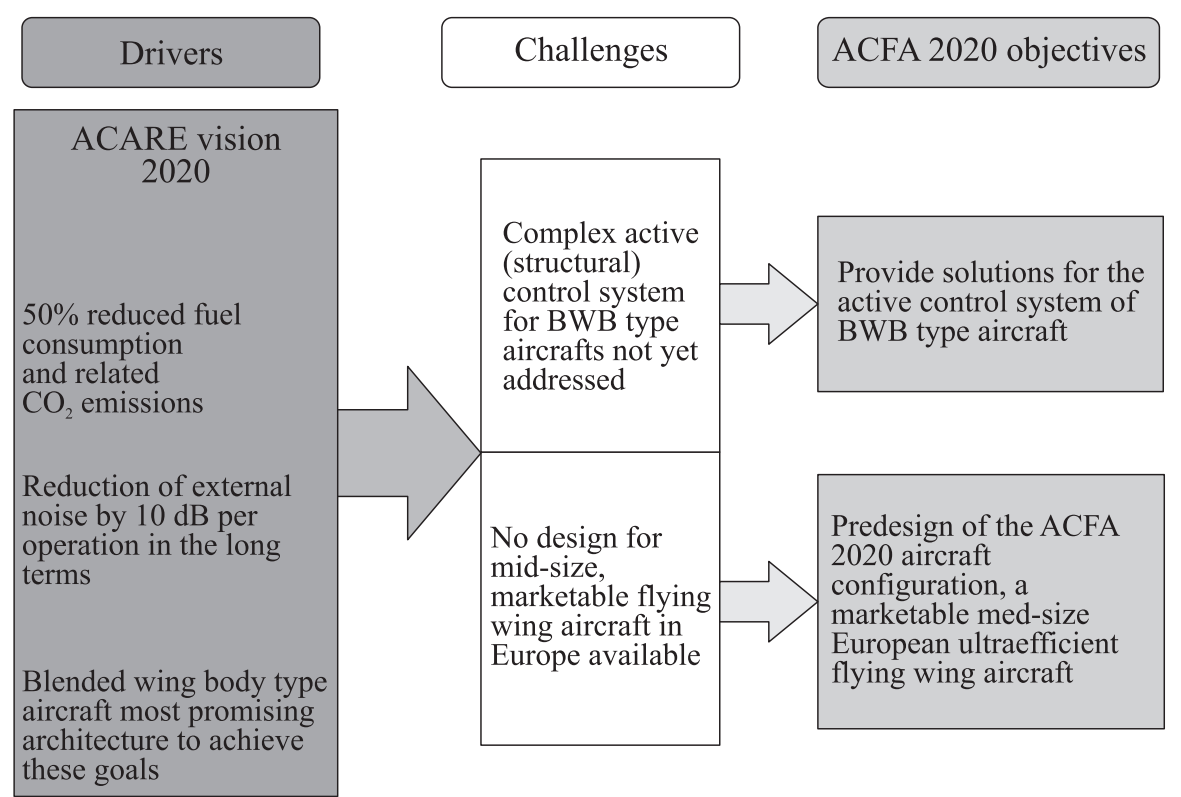

Figure 1 Main drivers and goals for ACFA 2020

addressed in ACFA 2020 is the complex flight control and structural control system required for such aircraft configurations.

As shown in Fig. 2, the work is organized in 4 technical subsequent work packages. An additional work package WP0 is dedicated to the management of the project and the dissemination as well as exploitation of results. The core of the ACFA 2020 project is work package 3 "Development \& Evaluation of active control concepts" where active control systems for BWB type aircraft are designed by a community of partners. The main objective of the designed control systems is to reduce structural vibrations and unwanted rigid body motions, on the one hand, and gust and manoeuvre loads, on the other. The reduced static and dynamic loads are the basis for a structural resizing performed in work package 4 of the ACFA 2020 aircraft configuration which is designed in work package 1.

Work package 2 deals with the generation of dynamic aircraft models which are required for the control design task. In order to be able to start with the investigations on control design as early as possible, in the project, in a first step, the models of the NACRE flying wing aircraft were created and after that, in a second phase, dynamic models of the ACFA 2020 have been generated. In both cases, the aeroelastic models are linearized, parameterized, and reduced to a reasonable order for the control design task. To be able to apply mod- 


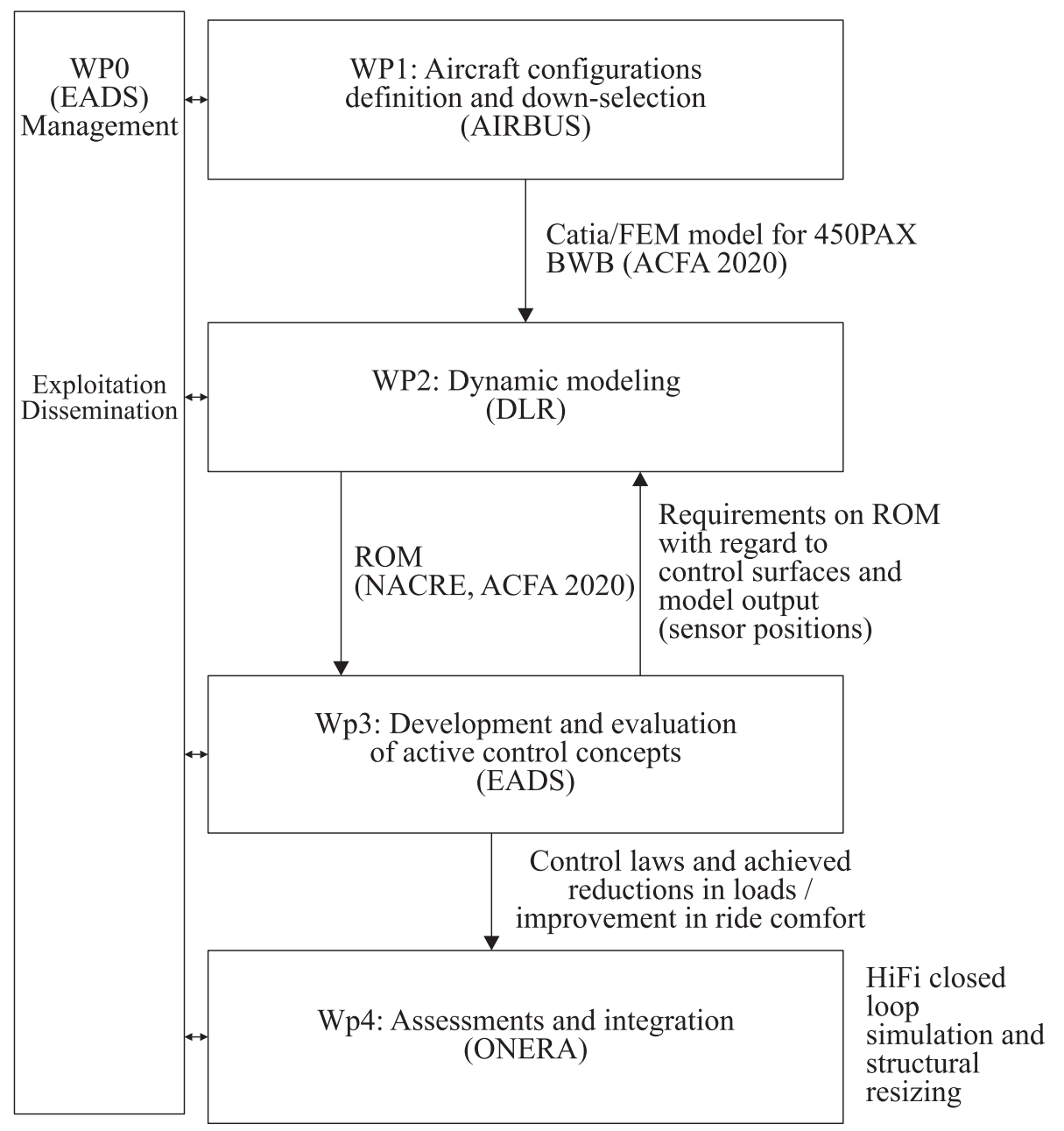

Figure 2 ACFA 2020 work-package structure

ern robust control design techniques, the parameterized reduced order models (ROM) are transformed by DLR to linear fractional transformation (LFT) models to cover the uncertainties. The control design work in work package 3 is focussed on the application of modern robust control design techniques as well as adaptive control. Major goal of the work package 3 is to compare the different control concepts providing the required handling qualities with respect to complexity, robustness and by evaluating the best achievable reductions in loads and improvements in ride comfort. Finally, in work package 4, the results are 
validated to some extent by performing higher fidelity simulations. Furthermore, a structural resizing is performed based on the achieved loads alleviation.

The project consortium comprises 13 partners from 9 countries who are listed with their major activities and acronyms used within this paper in the following:

- EADS Innovation Works (EADS), project coordinator, lead and technical contributions in WP3;

- Airbus Operations (AIRBUS), lead of WP1;

- Alenia Aeronautica S.p.A. (ALENIA), flutter analysis and structural modeling(WP2 and WP4);

- HELLENIC AEROSPACE INDUSTRY S.A. (HAI), aerodynamics (WP2 and WP4);

- Israel Aerospace Industries (IAI), adaptive, neural network control (WP3);

- Deutsches Zentrum für Luft- und Raumfahrt e.V. (DLR), lead of WP2, technical contributions to all WPs;

- Office National d'Etudes et Recherches Aérospatiales (ONERA), lead of WP4, technical contributions to all WPs;

- Swedish Defence Research Agency (FOI), aerodynamics and HiFi simulations, task leader (WP2 and WP4);

- Technical University Munich (TUM), conceptual aircraft design (Institute for Aerospace Systems), dynamic modeling, structural sizing, task lead in WP2 and WP3 (Institute of Lightweight Structures and unsteady aerodynamics (Institute of Aerodynamics and Fluid Mechanics);

- Vienna University of Technology (TUV), robust control design techniques, task lead in WP3;

- Czech Technical University (CTU), Dynamic modeling (Order reduction, comfort modeling - Faculty of Mechanical Engineering) and robust control design (Institute of Information Theory and Automation);

- National Technical University Athens (NTUA), Aerodynamics and HiFi simulation (WP2 and WP4); and

- Bialystok Technical University (BTU), stability and convergence analysis for adaptive feedforward control concept (WP3). 


\section{MAJOR RESULTS}

\subsection{Aircraft Design}

Conceptual designs for two configurations, a 450-passenger BWB and an ultrawide-body aircraft with CWB were performed by Technical University of Munich and AIRBUS (Fig. 3). Both aircrafts were designed for the same mission roughly defined by the following parameters:

- long range cruise Mach number: 0.85;

- maximum range at maximum passenger payload: $7200 \mathrm{~nm}$;

- approach speed should be $<150 \mathrm{kt}$;

- maximum operating Mach number (MMO): 0.89;

- maximum operating velocity (VMO): $340 \mathrm{kts}$ CAS (calibrated air speed); and

- maximum cruise altitude: $43,100 \mathrm{ft}$.

The concurrent design was mainly done to compare the BWB configuration to a more conventional design, in particular, with respect to fuel efficiency. It turned out that the BWB aircraft shows about $13 \%$ better fuel efficiency compared to the CWB aircraft which is mainly due to lower weight of the BWB and better aerodynamic performance. Therefore, the BWB configuration was retained for the further work on active control concepts.

The final BWB configuration has a very blended shape between the center body and the outer wing in order to get a smooth load and lift distribution along the blended wing span. A quite high sweep and aft position of the wing are important to make the aircraft stable. The BWB provides a lot of space underneath the cabin for the center tank and so, it can be efficiently used to trim the aircraft during cruise. However, this makes the fuel system safety critical because it must be operational to keep the aircraft center of gravity

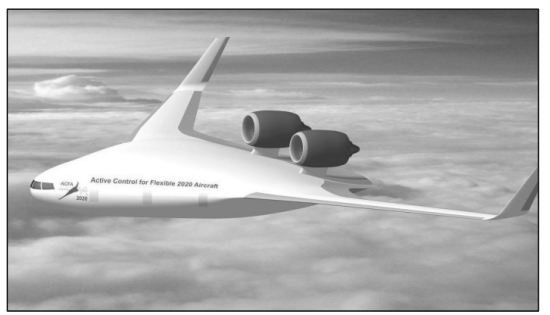

(a)

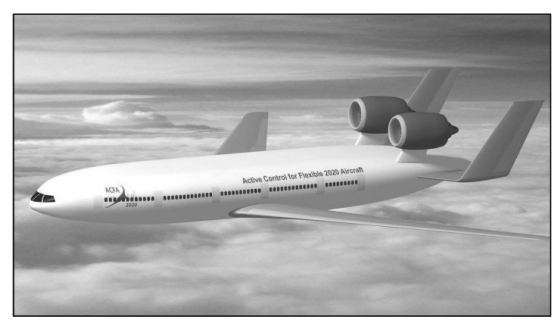

(b)

Figure 3 ACFA 2020 aircraft configurations: (a) BWB and (b) CWB 
within an acceptable range. More details about fuel management concepts can be found in [19]. The longitudinal control is done by rear elevons located both on the center body and on the wing (except aft of the engine pylons). The area dedicated to those movables is rather high in order to provide sufficient control authority. The lateral control is critical on this aircraft, especially in the one engine out case, and is achieved by split ailerons and rather high winglets equipped with a rudder. A detailed description of the design can be found in [16].

Figure 4 illustrates the main control surfaces available at the ACFA 2020 BWB.

Two engines are located on the upper side of the center body; so, it is expected to provide efficient shielding for the fan noise. Unfortunately, in the frame of the ACFA 2020 project, it was not possible to assess the exterior noise benefit of this configuration vs. a classic aircraft of the same size but the noise benefit is revisited in the FP7 project OpenAir [26] which is dealing with novel noise reduction technologies.

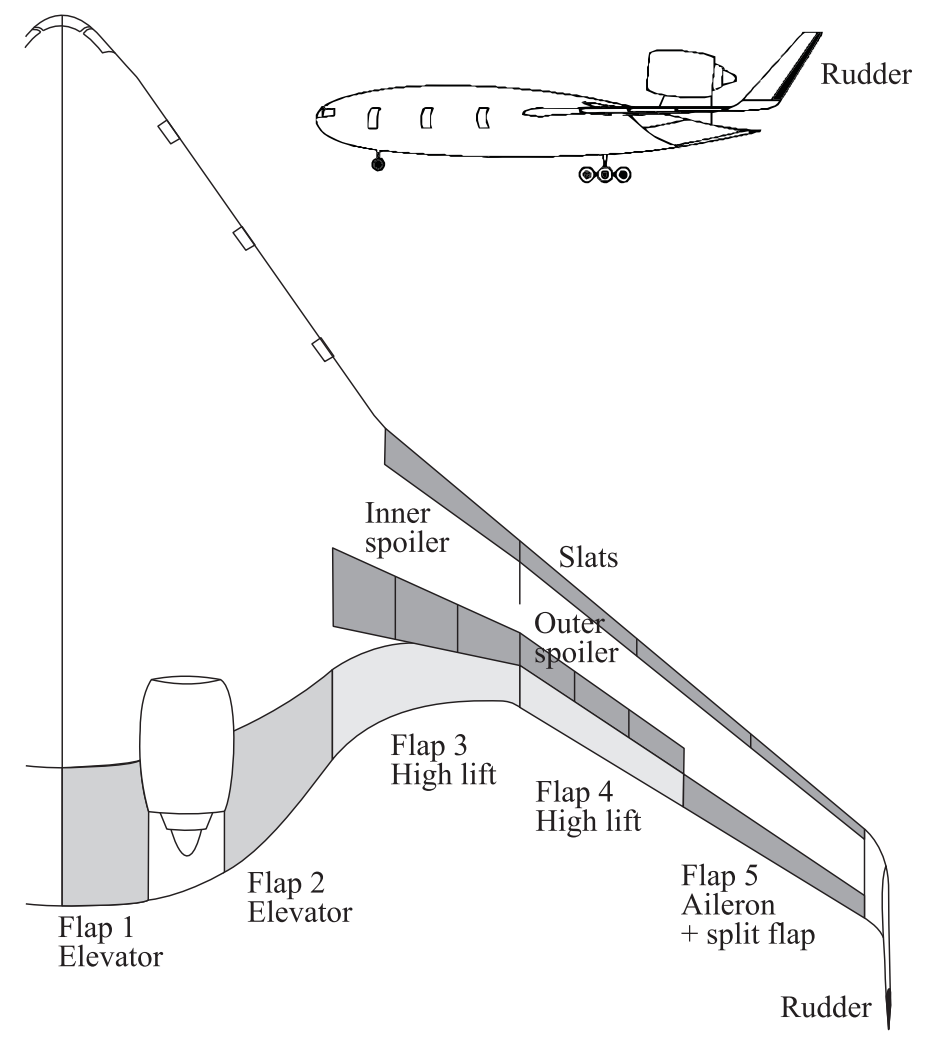

Figure 4 ACFA 2020 BWB control surfaces 


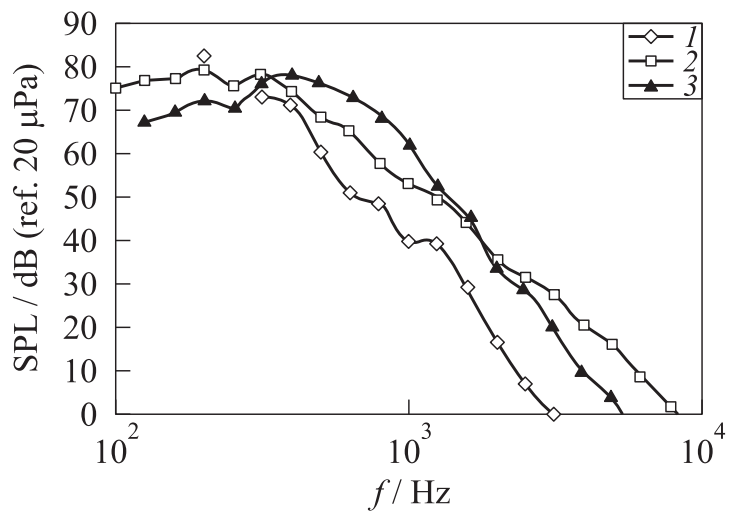

Figure 5 Comparison of interior noise levels for BWB (1), CWB (2), and a conventional generic single aisle (GSA) aircraft (3)

However, a small study on interior noise comfort was performed with respect to turbulent boundary layer noise, which is the major noise source in cruise condition. Statistical energy analysis was applied for a portion of the cargo/cabin area, whereby some optimization of the cabin treatment was performed. As shown in Fig. 5, the BWB shows significant lower noise levels than the CWB and both aircrafts are quieter than a generic conventional single aisle aircraft configuration which was used as an additional reference. The mean overall sound pressure level (SPL) of the BWB is about $3 \mathrm{~dB}$ below the SPL of the CWB configuration which is quite significant. The main reason behind is the large distance between the cabin and the outer skin which leads to a high transmission loss already at low frequencies. With respect to cabin noise, one can conclude that the BWB configuration is quite favourable.

\subsection{Dynamic Modeling}

The generation of aeroelastic parameterized reduced-order models for the NACRE and ACFA 2020 BWB was a joint effort of numerous partners (DLR, FOI, ONERA, HAI, NTUA, TUM). In order to consider several fuel/payload cases, a set of structural models representing the various mass configurations were developed for both aircrafts. A structural model was provided by the NACRE consortium but was significantly refined to make it applicable for structural dynamics investigations. The steady and unsteady aerodynamics for the NACRE and the ACFA 2020 BWB have been calculated for a variety of flight conditions, i. e., Mach numbers, dynamic pressure, center of gravity positions, and mass cases. In order to be able to use spoiler devices for the controller 


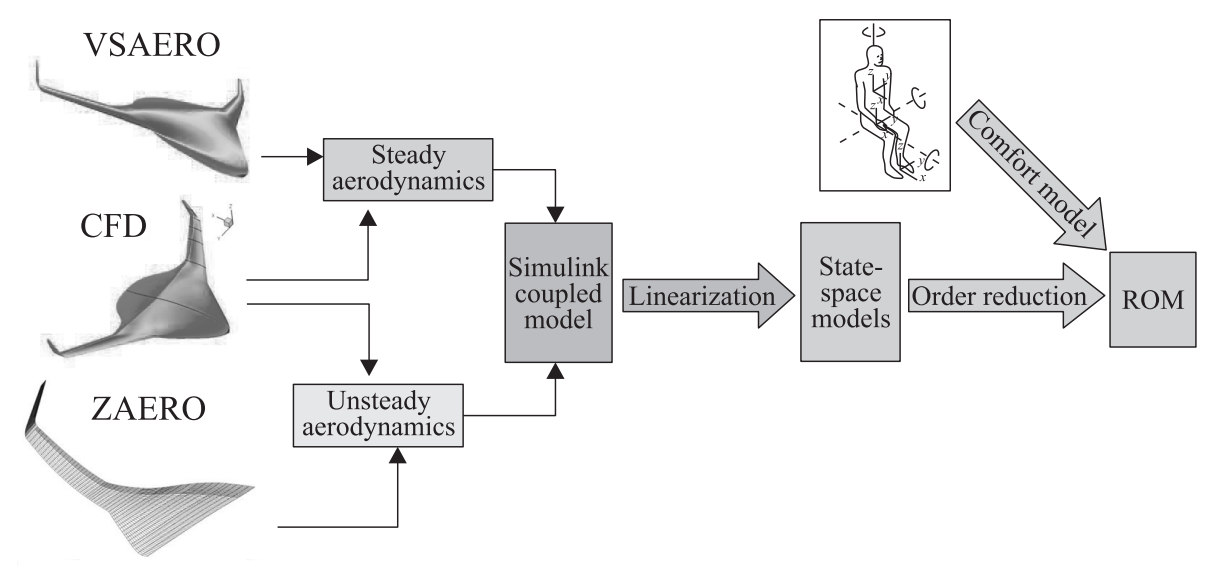

Figure 6 Model generation process (source: Institute of Lightweight Structures TUM)

design, aerodynamic loads (lift, drag, and pitching moment) were calculated by using an unsteady vertex blob code. The whole process and tool chain applied for the model generation is illustrated in Fig. 6 .

For the control system design, low-order models are used which comprises only 2-6 flexible modes and using simplified linear actuator and sensor models. By application of adequate order reduction methods (balanced truncation, singular perturbation approximation) it is assured that the input/output behavior is preserved in an optimal way. During the control design process, higher order models comprising around 12 modes and also more detailed nonlinear actuator and sensor models are used to validate the robustness of the controller designs. Finally, full-order models (80 modes for the ACFA 2020 BWB) are used to evaluate the loads for the structural resizing.

Model inputs are the control surface deflections and engine thrust as well as gusts. For the modeling of the gust response, a set of gust inputs have been considered whereby as inputs, two-dimensional (2D) von Karman turbulence models are used. By a Markovian representation of the vertical turbulence for a particular aircraft speed (TAS) at predefined locations ahead of the aircraft and on the aircraft, the signals are generated showing the theoretical spectra and cross spectra of 2D von Karman turbulence [27].

Model outputs are the rigid body motion, accelerations at preselected positions for vibration damping [7] as well as cut forces and moments (Fig. 7) for estimation of control performance and critical cases with respect to loads.

Regarding the comfort criteria, CTU developed filters (e.g., sea sickness) delivering comfort outputs based on the states of the aeroelastic models [10].

More details on the model generation process can be found in [18]. 

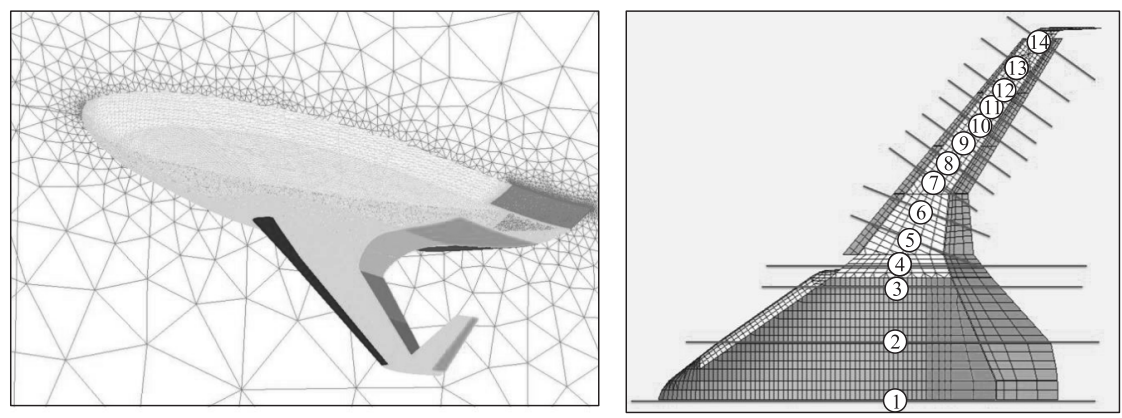

Figure 7 Computational fluid dynamics (CFD) mesh for the ACFA BWB (FOI) and positions for cut forces and moments (TUM). (Refer color plate, p. VI.)

\subsection{Control Concepts}

Control design for large flexible aircraft and, in particular, the BWB configuration is a quite challenging task due to numerous objectives and severe constraints which have to be taken simultaneously into account. Major goal of the ACFA 2020 project is to investigate and to combine various modern robust control and LPV (Linear Parameter Varying) design techniques as well as adaptive control concepts. As illustrated in Fig. 8, basic feedback control is augmented by an additional feedforward control path to alleviate the effect of turbulence and gusts. To achieve the desired handling qualities and to alleviate manoeuver loads, also

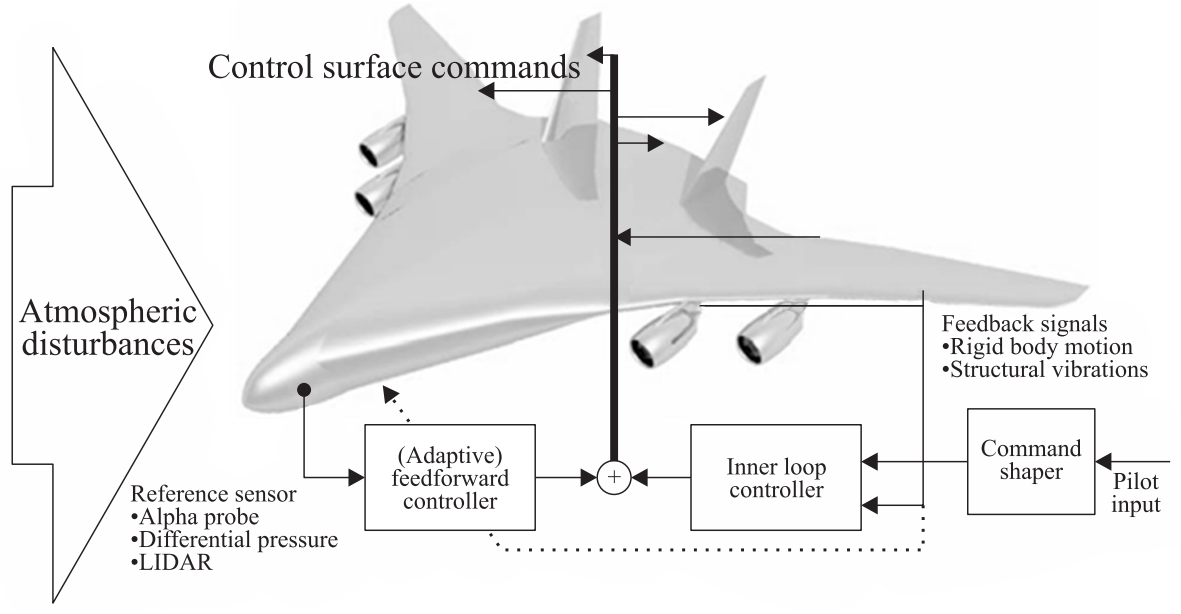

Figure 8 Basic outline of investigated control concepts 


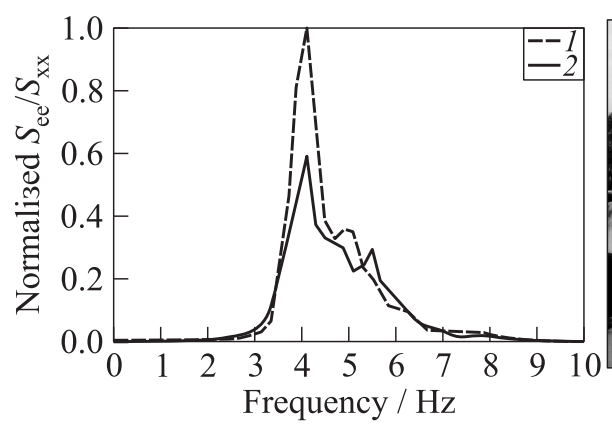

(a)

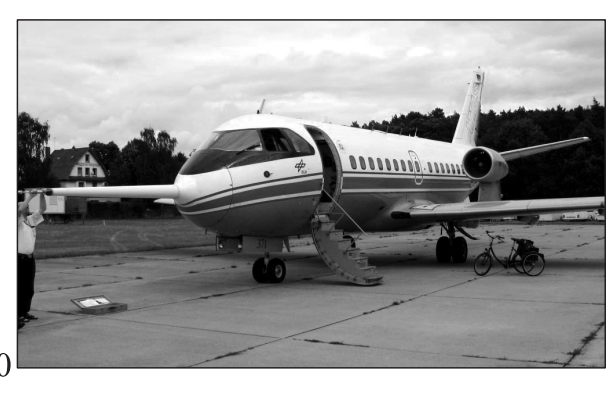

(b)

Figure 9 Vibration reduction for engine pylon mode with adaptive feedforward control $(a)$ at ATTAS aircraft $(b): 1$ - vibration controll off; and 2 - adaptive vibration control on

a feedforward control path for pilot commands is used. Robust control concepts are investigated, in particular, by TUV and CTU.

A large variety of design methods $\left(H_{\infty^{-}}, \mathrm{H}_{2}\right.$-optimal control design, $H_{\infty}$ fixedorder optimization methods) and robust and scheduled extensions of these methods have been applied. Details can be found in $[4,8,9,11,20,21,24]$. Furthermore, modern convex synthesis design techniques are investigated by ONERA [23]. An adaptive multiple input multiple output (MIMO) feedforward control concept [6] is investigated by EADS Innovation Works to mitigate turbulence-induced vibrations and related loads. To validate the real-time behavior of the adaptation, a flight test with the DLR Advanced Technologies Testing Aircraft (ATTAS) has been performed [3]. This aircraft is already equipped with sensors and actuators to flight test active feedforward gust and vibration control concepts [28-30].

A main result with control of engine pylon bending mode is shown in Fig. 9. The power spectrum of the lateral engine acceleration is related to the spectrum of the nose boom alpha signal with and without control in order to get a performance measure which is independent from the excitation level. The alpha signal was the most suitable available reference for the turbulence strength. The signal power of the lateral engine acceleration was reduced by $40 \%$ by the converged feedforward controller. This value is mainly determined by the correlation between the turbulence measurement with the alpha probe and the real excitation of the mode to be controlled. The adaptive feedforward controller minimizes the $\mathrm{H}_{2}$-norm of the error signal, which is usually a modal sensor, i. e., an appropriate combination of accelerations measured at the structure to control. In principle, the converged controller can be always active which provides robust performance of the feedforward loop also in case of plant uncertainties or plant variations with time. Alternatively, adaptation could be just used during 


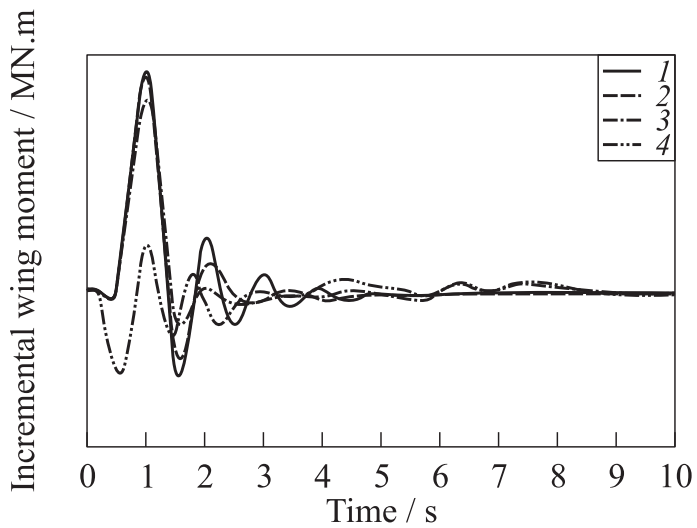

Figure 10 Example for the effect of gust load alleviation by combined feedback/feedforward control for the NACRE aircraft: 1 - controlled aircraft without GLAS; 2 - with active wing bending damping; 3 - with dynamic feedforward GLAS; and 4 - with complete GLAS

flight testing and transformed into a fixed or scheduled controller for regular operation.

The adaptive feedforward control concept has been also successfully applied to the NACRE BWB to control the first wing bending mode. This significantly improves the ride comfort but the effects on loads (wing root moments) were partially detrimental, in particular, for discrete gusts which are typically most important for the structural sizing. Therefore, optimized nonlinear feedforward gust load alleviation concepts have been developed in addition. The basic concept and main results can be found in [3]. As illustrated in Fig. 10, it can be very beneficial to add actively damping to the structure by feedback control and to combine this with a feedforward gust load alleviation system deploying the spoilers when entering a gust. For the ACFA 2020 BWB, an even more advanced gust loads alleviation system (GLAS) using optimization techniques to determine the best sequence of control surface deployments has been developed. Details can be found in [22].

In addition, adaptive feedback control has been successfully considered by IAI for the NACRE aircraft and is under evaluation for the ACFA 2020 BWB. A neural network controller is used to augment a classical controller, whereby the adaptive part is mainly directed to structural control.

\section{SUMMARY AND OUTLOOK}

The BWB concept proofed to be very efficient with respect to fuel burn also for medium sized transport aircraft (450PAX). Compared to a more conventional 
configuration by application of the same engine technology more than $13 \%$ less fuel burn has been estimated for the BWB aircraft. Investigations from Boeing in [31] estimated even $32 \%$ less fuel burn for BWB Boeing design of similar size compared to an A380. The major part of the project deals with the development of advanced active control concepts, in particular, to achieve a significant loads reduction and high ride comfort. The development of control laws for the ACFA 2020 is still on-going. Major results are presented in [20-22, 24, 25]. Already for the NACRE aircraft, it was shown that the ride comfort can be largely improved by a combined feedback and adaptive feedforward control concept. The adaptive feedforward control concept to reduce turbulence-induced vibrations was in addition validated by flight tests with the ATTAS aircraft. Loads due to discrete gusts can be also significantly alleviated by combined feedback and feedforward concepts.

In a final step, the simulations based on reduced-order models will be validated by higher fidelity simulations using CFD tools in closed loop with the developed control laws. For this purpose, Simulink is used to simulate the controller part and is directly coupled with CFD tools from FOI and NTUA. Furthermore, the weight savings due to active loads alleviation will be evaluated by resizing the ACFA 2020 BWB.

So far, the ACFA 2020 project showed that the BWB concept is quite attractive mainly with respect to fuel burn and that it can be further improved by enhanced active control. Nevertheless, there is still a long way to go to bring such an unconventional configuration to reality. From aeromechanics point of view, the next most interesting steps after the ACFA 2020 project would be to investigate the low-speed handling qualities of the BWB in high lift configuration by a scaled demonstrator aircraft. In this framework, it would be also important to optimize the aerodynamics and to generate a full nonlinear aerodynamic dataset for the BWB also in high lift configuration.

\section{ACKNOWLEDGMENTS}

The research described within this paper has received funding from the European Community's 7th Framework Programme (FP7/2007-2013) under grant agreement No. 213321.

My special thanks are directed to the whole project team for the extraordinary engagement and enthusiasm I experienced throughout the project. In this connection, I would also like to give warm thanks to the group of personalities forming the ACFA 2020 Scientific Advisory Group for their very valuable comments and recommendations given during and after the major project reviews. Members of this group are: Dagfinn Gangsaas, Gary Balas, University of Minnesota, Mark Lowenberg, University of Bristol, and Ilkay Yavrucuk, Middle East Technical University. 


\section{REFERENCES}

1. Frota, J. 2011. New aircraft concept research in NACRE - a five-year synthesis (2005-2010). Aerodays. Madrid, Spain.

2. Wildschek, A., R. Maier, M. Hromčík, T. Haniš, A. Schirrer, M. Kozek, C. Westermayer, and M. Hemedi. 2009. Hybrid controller for gust load alleviation and ride comfort improvement using direct lift control flaps. 3rd European Conference for Aerospace Sciences (EUCASS 2009). Versailles, Paris.

3. Wildschek, A., R. Maier, K.-U. Hahn, D. Leißling, M. Preß, and A. Zach. 2009. Flight test with an adaptive feed-forward controller for alleviation of turbulence excited structural vibrations. AIAA Guidance, Navigation, and Control Conference. Chicago.

4. Westermayer, C., A. Schirrer, M. Hemedi, M. Kozek, and A. Wildschek. 2009. Robust hinf flight and load control of a flexible aircraft using a 2DOF multi-objective design. CACS Automatic Control Conference (International). Taipei.

5. Wildschek, A., F. Stroscher, Th. Klimmek, Z. Šika, T. Vampola, M. Valášek, D. Gangsaas, N. Aversa, and A. Berard. 2009. Gust load alleviation on a large blended wing body airliner. ICAS 2010. Nice.

6. Wildschek, A. 2009. An adaptive feed-forward controller for active wing bending vibration alleviation on large transport aircraft. Dissertation. Technische Universität München.

7. Hemedi, M., A. Schirrer, C. Westermayer, and M. Kozek. 2010. Integrated inputoutput selection strategy for robust control of complex parameter varying systems. 10th Conference (International) on Motion and Vibration Control (MOVIC 2010). Tokyo, Japan.

8. Schirrer, A., C. Westermayer, M. Hemedi, and M. Kozek. 2010. A comprehensive robust control design and optimization methodology for complex flexible-structure systems. 18th Mediterranean Conference on Control and Automation. Marrakech, Morocco.

9. Schirrer, A., C. Westermayer, M. Hemedi, and M. Kozek. 2010. LQ-based design of the inner loop lateral control for a large flexible BWB-type aircraft. 2010 IEEE Conference (International) on Control Applications. Yokohama, Japan.

10. Zuziak, P., Z. Šika, M. Valášek, T. Vampola, and Th. Klimmek. 2010. Vibration control of flexible aircraft with respect to passengers comfort. ISMA 2010. Leuven.

11. Westermayer, C., A. Schirrer, M. Hemedi, and M. Kozek. 2010. Linear parametervarying control of a large blended wing body flexible aircraft. 18th IFAC Symposium on Automatic Control in Aerospace. Nara, Japan.

12. Petersson, Ö., M. Leitner, and F. Stroscher. 2010. Structural optimization framework for aircraft subject to transient maneuver and gust loads. 13th AIAA/ISSMO Multidisciplinary Analysis and Optimization Conference 2010. Fort Worth, TX.

13. Stroscher, F., Ö. Petersson, and M. Leitner. 2010. Aircraft structural optimization subject to flight loads: Application to a wide body commercial aircraft configuration. EASN Workshop on Aerostructures. Paris. 1. 
14. Petersson, Ö., F. Stroscher, and H. Baier. 2010. Multidisciplinary optimisation of aircraft wings including gust loads. 2nd RAeS Aircraft Structural Design Conference. London.

15. Meyer, M., and C. Breitsamter. 2010. High fidelity analysis of the steady and unsteady aerodynamics of the blended wing body ACFA2020 (Active control for flexible 2020 aircraft). DGLR-Fach-Symposium der STAB. Berlin, Germany. 17.

16. Paulus, D., T. Salmon, B. Mohr, C. Roessler, Ö. Petersson, F. Stroscher, H. Baier, and M. Hornung. 2013. Configuration selection for a 450-passenger ultraefficient 2020 aircraft. In: Progress in flight dynamics, guidance, navigation, control, fault detection, and avionics. Eds. Ch. Vallet, D. Choukroun, Ch. Philippe, G. Balas, A. Nebylov, and O. Yanova. EUCASS advances in aerospace sciences book ser. Moscow: TORUS PRESS. 6:601-18.

17. Meyer, M., and Ch. Breitsamter. 2013. Influencing the aerodynamics of the ACFA2020 aircraft with flap and trailing edge device oscillations. In: Progress in flight dynamics, guidance, navigation, control, fault detection, and avionics. Eds. Ch. Vallet, D. Choukroun, Ch. Philippe, G. Balas, A. Nebylov, and O. Yanova. EUCASS advances in aerospace sciences book ser. Moscow: TORUS PRESS. 6:61934.

18. Stroscher, F., Z. Sika, and Ö. Petersson. 2013. Reduced order model of a blended wing body aircraft configuration. In: Progress in flight dynamics, guidance, navigation, control, fault detection, and avionics. Eds. Ch. Vallet, D. Choukroun, Ch. Philippe, G. Balas, A. Nebylov, and O. Yanova. EUCASS advances in aerospace sciences book ser. Moscow: TORUS PRESS. 6:635-50.

19. Wildschek, A., F. Stroscher, T. Haniš, and T. Belschner. 2013. Fuel management system for cruise performance optimization on a large blended wing body airliner. In: Progress in flight dynamics, guidance, navigation, control, fault detection, and avionics. Eds. Ch. Vallet, D. Choukroun, Ch. Philippe, G. Balas, A. Nebylov, and O. Yanova. EUCASS advances in aerospace sciences book ser. Moscow: TORUS PRESS. 6:651-70.

20. Haniš, T., V. Kučera, and M. Hromčík. 2013. Low order $H_{\infty}$ optimal control for ACFA blended wing body aircraft. In: Progress in flight dynamics, guidance, navigation, control, fault detection, and avionics. Eds. Ch. Vallet, D. Choukroun, Ch. Philippe, G. Balas, A. Nebylov, and O. Yanova. EUCASS advances in aerospace sciences book ser. Moscow: TORUS PRESS. 6:671-84.

21. Westermayer, C., A. Schirrer, M. Hemedi, and M. Kozek. 2013. An $H_{\infty}$ full information approach for the feedforward controller design of a large blended wing body flexible aircraft. In: Progress in flight dynamics, guidance, navigation, control, fault detection, and avionics. Eds. Ch. Vallet, D. Choukroun, Ch. Philippe, G. Balas, A. Nebylov, and O. Yanova. EUCASS advances in aerospace sciences book ser. Moscow: TORUS PRESS. 6:685-706.

22. Wildschek, A., T. Haniš, and F. Stroscher. 2013. L $\infty_{\infty}$-optimal feedforward gust load alleviation design for a large blended wing body airliner. In: Progress in flight dynamics, guidance, navigation, control, fault detection, and avionics. Eds. Ch. Vallet, D. Choukroun, Ch. Philippe, G. Balas, A. Nebylov, and O. Yanova. EUCASS advances in aerospace sciences book ser. Moscow: TORUS PRESS. 6:707-28. 
23. Demourant F., and G. Ferreres. 2013. A linear parameter-varying multiobjective control law design based on Youla parametrization for a flexible blended wing body aircraft. In: Progress in flight dynamics, guidance, navigation, control, fault detection, and avionics. Eds. Ch. Vallet, D. Choukroun, Ch. Philippe, G. Balas, A. Nebylov, and O. Yanova. EUCASS advances in aerospace sciences book ser. Moscow: TORUS PRESS. 6:729-48.

24. Schirrer, A., C. Westermayer, M. Hemedi, and M. Kozek. 2013. Robust laterial blended wing body aircraft feedback control design using a parameterized LFR model and DGK-iteration. In: Progress in flight dynamics, guidance, navigation, control, fault detection, and avionics. Eds. Ch. Vallet, D. Choukroun, Ch. Philippe, G. Balas, A. Nebylov, and O. Yanova. EUCASS advances in aerospace sciences book ser. Moscow: TORUS PRESS. 6:749-66.

25. Kučera, V., and M. Hromčík. 2013. Delay-based signal shapers and ACFA 2020 blended wing body flight control system. In: Progress in flight dynamics, guidance, navigation, control, fault detection, and avionics. Eds. Ch. Vallet, D. Choukroun, Ch. Philippe, G. Balas, A. Nebylov, and O. Yanova. EUCASS advances in aerospace sciences book ser. Moscow: TORUS PRESS. 6:767-77.

26. Kors, E. 2010. OPENAIR - OPtimisation for low Environmental Noise impact AIRcraft. INTERNOISE 2010. Lisbon, Portugal.

27. Imbert, N., Ph. Mouyon, and G. Montseny. 2000. State representation and simulation of 2D turbulent wind. AIAA SMT Proceedings. Denver, USA.

28. Hahn, K.-U., and R. Koenig. 1992. ATTAS flight test and simulation results of the advanced gust management system LARS. AIAA Atmospheric Flight Mechanics Conference. Hilton Head Island, SC.

29. Hecker, R. S., and K.-U. Hahn. 2007. Advanced gust load alleviation system for large flexible aircraft. 1st CEAS European Air and Space Conference. Berlin, Germany.

30. Wildschek, A., and R. Maier. 2008. Integrated adaptive feed-forward control of atmospheric turbulence excited rigid body motions and structural vibrations on a large transport aircraft. American Control Conference 2008. Seattle, Washington.

31. Liebeck, R.H. 2004. Design of the blended wing body subsonic transport. J. Aircraft 41(1):10-25. 


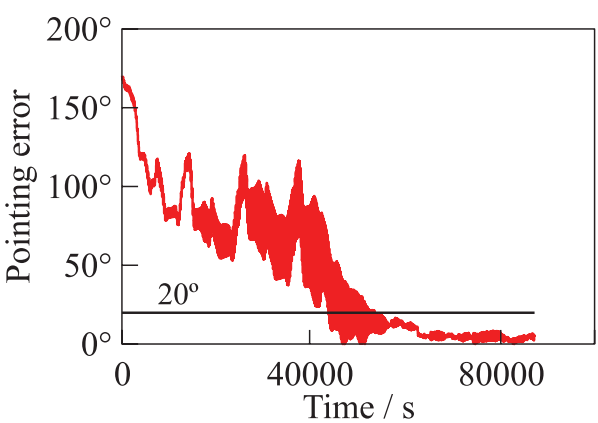

(a)

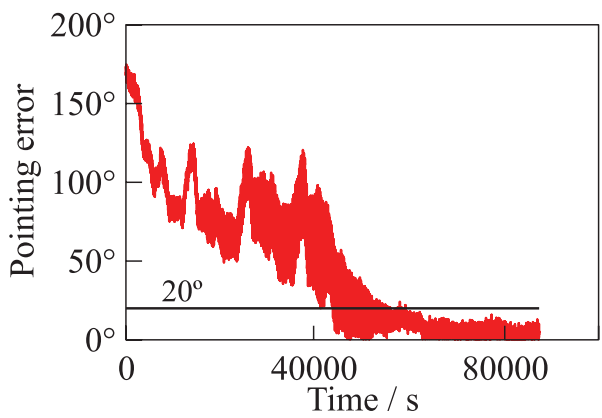

(b)

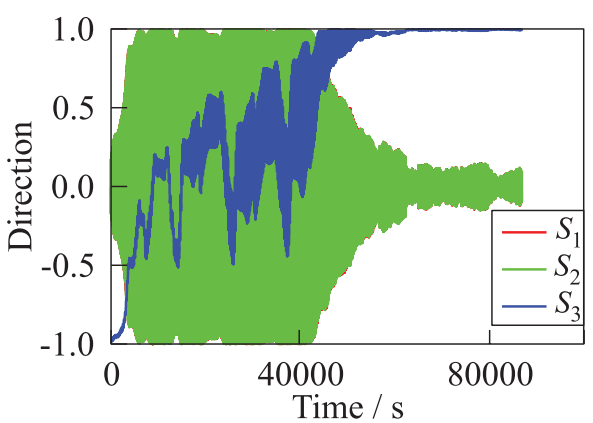

(c)

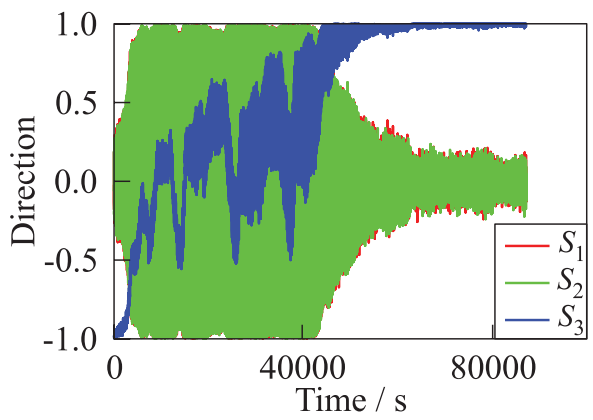

(d)

Figure 8 Fine Sun pointing; Sun pointing is achieved; angular rates are estimated: (a) Sun pointing accuracy; (b) Sun pointing accuracy as measured; (c) direction of Sun in $B$; and $(d)$ direction of Sun in $B$ as measured. (Refer Reijneveld and Choukroun, p. 207.)
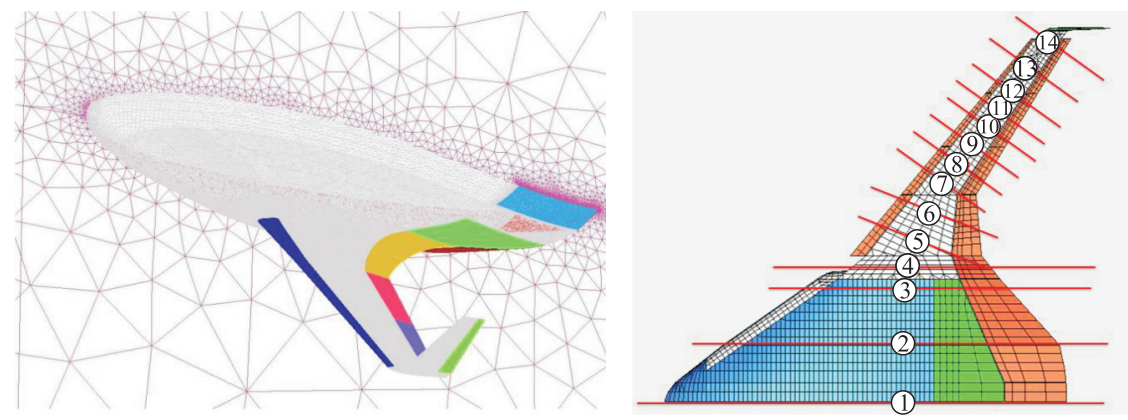

Figure 7 Computational fluid dynamics (CFD) mesh for the ACFA BWB (FOI) and positions for cut forces and moments (TUM). (Refer Maier, p. 594.) 